\title{
Structure Inhomogeneity and Failure Analysis of Modern Pipe Steels
}

\author{
A.A. Kazakov, ${ }^{*}$ O.V. Kurochkina, ${ }^{*}$ E.I. Kazakova, ${ }^{*}$ and D.V. Kiselev * \\ * Steel and Alloys Department, Saint-Petersburg State Polytechnical University, Russia, \\ Saint-Petersburg, Polytechnicheskaya, 29, 195251
}

It is well known that brittle fracture tendency of steels at low environmental temperatures depends on its structural inhomogeneity. It is reasonable to use Image Analyzer (IA) for quantitative estimation of the structure therefore IA may be an effective tool for the interpretation of failure analysis. The influence of structural inhomogeneity upon the failure behavior at low temperature environment during drop weight tear test (DWTT) and impact test is illustrated on the example of low carbon ferrite-bainitic pipeline steels.

It was established that the percent composition of ductile fracture after DWTT as well as impact numbers at low environmental temperatures were definitely dependent on structural inhomogeneity of plates. Structural inhomogeneity of ferrite-bainitic steels was a result of inadequate process of controlled rolling with accelerated cooling. It is formed by the coarse bainitic regions with lath morphology elongated along the rolling direction. Its elongated interphase boundaries with ferrite are decorated by cementite and have an adverse effect on the properties of steel at low environmental temperatures.

The method of revealing lath morphology bainitic regions with successful estimation by image analysis was developed. 10\% aqueous sodium metabisulphite (SMB) solution was used for tint etching. Further investigations were carried out in polarized light of optical microscope at $200 \mathrm{X}$ magnification (Fig.1a) using color thresholding feature of Thixomet Image Analyzer (be consistent with next paragraph) to reveal the fields of coarse lath morphology bainite (Fig.1b).

The volume fraction of bainitic regions with lath morphology, the longest dimension of interphase boundaries along the deformation axis fixed as average value from three maximum lengths of the regions $\left(D_{\mathrm{avg}}^{3 \max }\right)$, the volume fraction of bainitic regions with lath morphology with various dimensional groups were estimated on panoramic images of the structure using special plug-in of Thixomet Image Analyzer.

It was determined that the results of the drop weight test at $-20^{\circ} \mathrm{C}$ were well defined by the volume fraction and the length of the lath morphology bainite regions (Fig.2a). There are large volume fraction and elongated interphase boundaries of bainitic regions with lath morphology $(800-1000 \mu \mathrm{m}$ and higher) in the structure of steels with low value of ductile fracture. In order to provide high values of ductile fracture (95\%) after DWTT the fraction of lath morphology bainite in the structure of steel has to be minimized and only single regions in length no more 500-700 $\mu \mathrm{m}$ are permitted (Fig.2a). Similar behavior was obtained during investigation of the samples after impact test at low environmental temperatures (Fig.2b).

Thus, it was established that the estimation of the volume fraction and the length of lath morphology bainite regions exhibited perfect correspondence with failure behavior at low environmental temperatures and could be critical characteristic of approval tests for low carbon pipeline steels. 


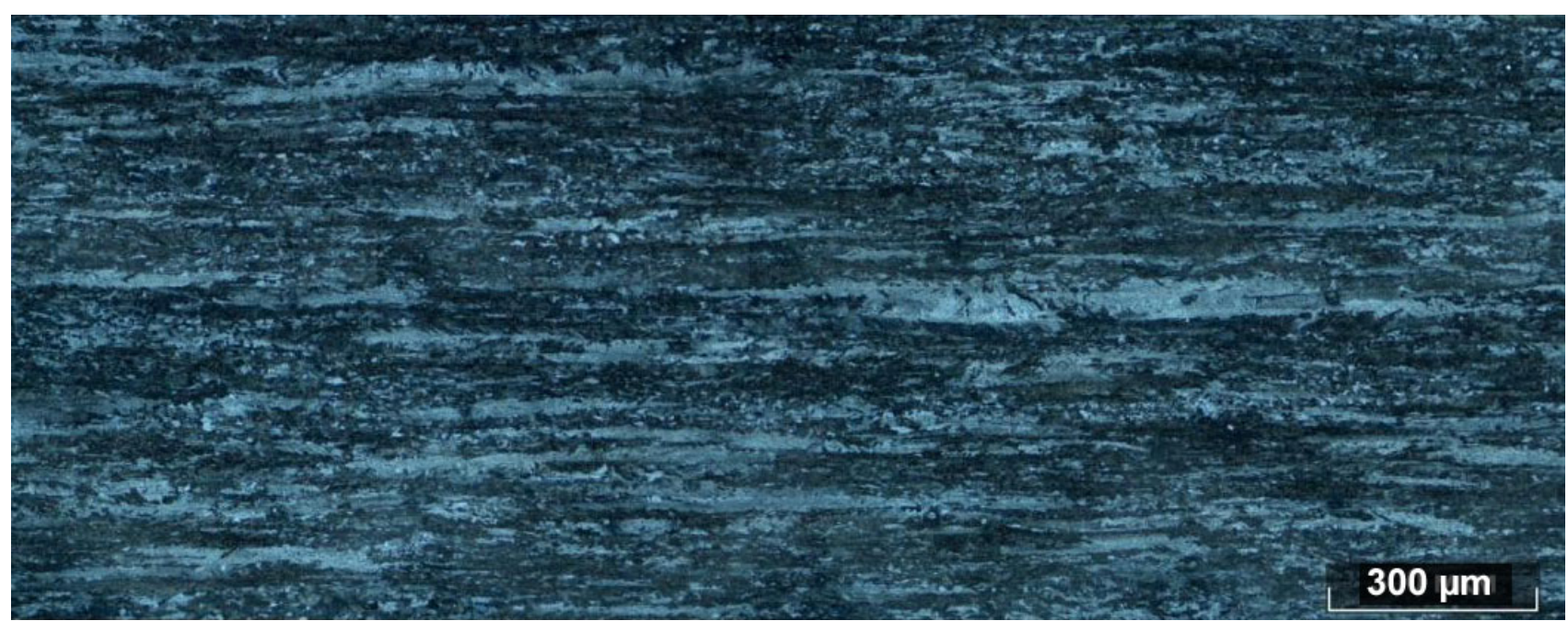

a)

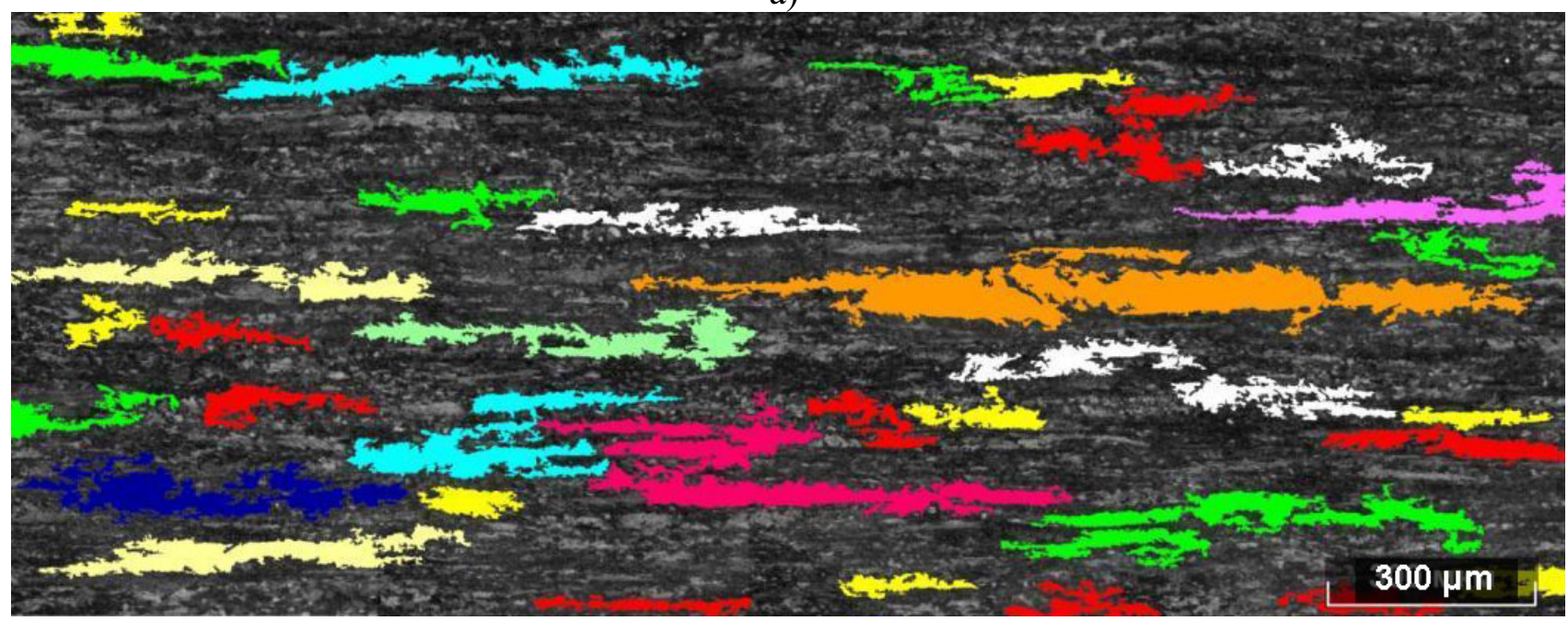

b)

Fig.1. Microstructure of pipe plate etched with $10 \%$ aqueous SMB in polarized light (a) and the fields of coarse lath morphology bainite regions, revealed by the color thresholding feature (b).

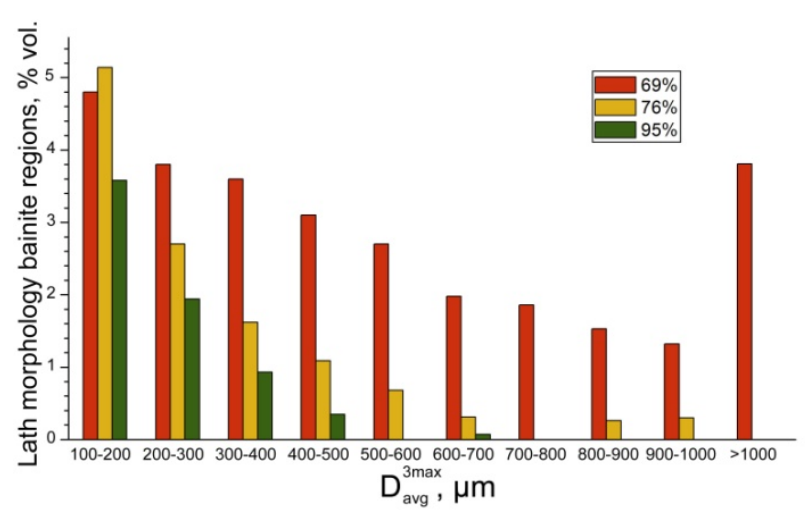

(a)

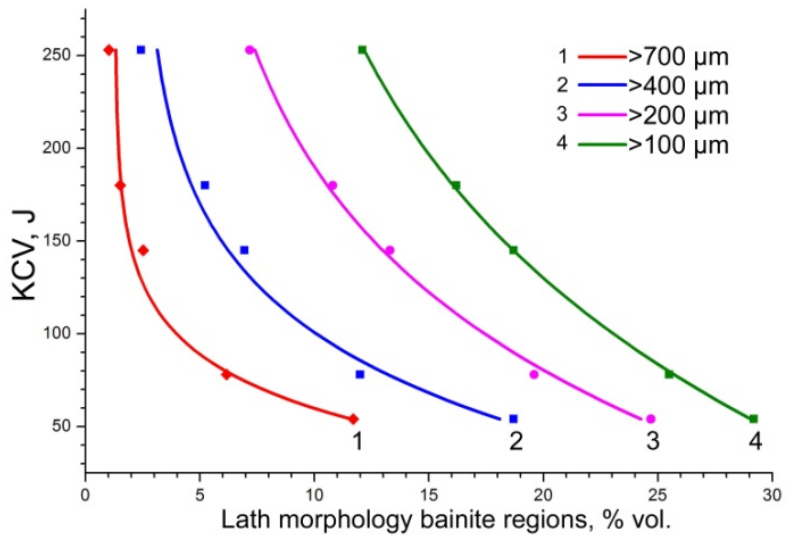

(b)

Fig.2. The results of the drop weight tear test at $-20^{\circ} \mathrm{C}$ (a) and impact number at $-40^{\circ} \mathrm{C}$ (b) versus volume fraction and the length of the of lath morphology bainite regions. 